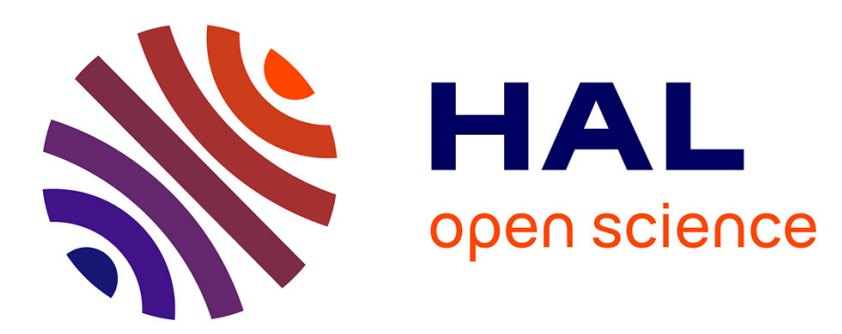

\title{
Muscle acylcarnitines during short-term fasting in lean healthy men
}

Maarten R Soeters, Hans P. Sauerwein, Marinus Duran, Ronald J. Wanders, Mariëtte T Ackermans, Eric Fliers, Sander M Houten, Mireille J Serlie

\section{> To cite this version:}

Maarten R Soeters, Hans P. Sauerwein, Marinus Duran, Ronald J. Wanders, Mariëtte T Ackermans, et al.. Muscle acylcarnitines during short-term fasting in lean healthy men. Clinical Science, 2009, 116 (7), pp.585-592. 10.1042/CS20080433 . hal-00479449

\section{HAL Id: hal-00479449 \\ https://hal.science/hal-00479449}

Submitted on 30 Apr 2010

HAL is a multi-disciplinary open access archive for the deposit and dissemination of scientific research documents, whether they are published or not. The documents may come from teaching and research institutions in France or abroad, or from public or private research centers.
L'archive ouverte pluridisciplinaire HAL, est destinée au dépôt et à la diffusion de documents scientifiques de niveau recherche, publiés ou non, émanant des établissements d'enseignement et de recherche français ou étrangers, des laboratoires publics ou privés. 


\section{Muscle acylcarnitines during short-term fasting in lean healthy men}

Maarten R. Soeters ${ }^{1}$, Hans P. Sauerwein ${ }^{1}$, Marinus Duran ${ }^{2}$, Ronald J. Wanders ${ }^{2}$, Mariëtte T. Ackermans $^{3}$, Eric Fliers ${ }^{1}$, Sander M. Houten ${ }^{2}$ and Mireille J. Serlie ${ }^{1}$

${ }^{1}$ Department of Endocrinology and Metabolism

${ }^{2}$ Department of Clinical Chemistry, Laboratory Genetic Metabolic Diseases

${ }^{3}$ Department of Clinical Chemistry, Laboratory of Endocrinology

Academic Medical Center, University of Amsterdam, Amsterdam, the Netherlands

\section{Corresponding author:}

M.R. Soeters MD, Dept. of Endocrinology and Metabolism, Academic Medical Center PO Box 22660, 1100 DD Amsterdam, the Netherlands

Phone: +31-20-5666849, fax: +31-20-6917682

E-mail: m.r.soeters@amc.uva.nl

Abbreviated title: Muscle acylcarnitines during fasting

Word count abstract: 240

Word count main text: 3093 


\section{Abstract}

The transition from the fed to the fasted resting state is characterized by, amongst others, changes in lipid metabolism and peripheral insulin resistance. Acylcarnitines have been suggested to play a role in insulin resistance besides other long-chain fatty acid metabolites. Plasma levels of long-chain acylcarnitines increase during fasting, but this is unknown for muscle long-chain acylcarnitines.

We studied whether muscle long-chain acylcarnitines increase during fasting and their relation with glucose/fat oxidation and insulin sensitivity in lean healthy humans.

After 14 and 62 hours of fasting, glucose fluxes, substrate oxidation, plasma and muscle acylcarnitines were measured before and during a hyperinsulinemic euglycemic clamp.

Hyperinsulinemia decreased long-chain muscle acylcarnitines after 14 hours of fasting but not after 62 hours of fasting. In both the basal state and during the clamp glucose oxidation was lower and fatty acid oxidation was higher after 62 hours vs. 14 hours of fasting. Absolute changes in glucose and fat oxidation in the basal vs. hyperinsulinemic state were not different. Muscle long-chain acylcarnitines did not correlate with glucose oxidation, fatty acid oxidation or insulin-mediated peripheral glucose uptake.

After 62 hours of fasting, the suppression of muscle long-chain acylcarnitines by insulin was attenuated compared to 14 hours of fasting. Muscle long-chain acylcarnitines do not unconditionally reflect fatty acid oxidation. The higher fatty acid oxidation during hyperinsulinemia after 62 vs. 14 hours of fasting although the absolute decrease in FAO was not different, suggests a different set point.

Key words: acylcarnitine, glucose and lipid oxidation, insulin resistance. 


\section{Introduction}

Short-term fasting can be defined as the first 72 hours of starvation in which progressive alterations in lipid and glucose metabolism occur [1;2]. The adaptation to short-term fasting is characterized by, amongst others, an increase in lipolysis with concomitant increases in plasma free fatty acids (FFA) and fatty acid oxidation (FAO) [1] and a decrease in peripheral insulin sensitivity and carbohydrate oxidation (CHO)[2-4].

To be oxidized, activated long-chain fatty acids can only cross the mitochondrial membranes as acylcarnitines (ACs)[5]. The coupling of an activated long-chain fatty acid to carnitine (3hydroxy-4- $N, N, N$-trimethylaminobutyric acid) is catalyzed by carnitineacyl(palmitoyl)transferase 1 (CPT1) on the outer mitochondrial leaflet [6]. CPT1 is considered to be the rate-limiting enzyme for long-chain fatty acid entry into the mitochondria and subsequent oxidation [5;7]. Furthermore CPT1 activity increases during fasting in animal studies [8]. Inside the mitochondrion, the AC is activated to acyl-CoA again by CPT2. The released carnitine is exchanged for a new incoming AC by the mitochondrial membrane protein carnitine-acylcarnitine-translocase (CACT) [6].

Plasma ACs are thought to reflect the mitochondrial acyl-CoA pool and AC profile analysis is the current standard for the diagnosis of FAO disorders at the metabolite level $[9 ; 10]$. Recently, muscle ACs have been implicated in insulin resistance via a currently unknown mechanism $[8 ; 11 ; 12]$. These studies suggested that increased beta-oxidation outpaces the tricarboxylic acid cycle (TCA) with subsequent inhibition of complete fatty acid oxidation via a high energy redox state (rising $\mathrm{NADH} / \mathrm{NAD}^{+}$and acetyl-CoA/CoA ratios). The accumulation of metabolic by-products (e.g. acylcarnitines) would then activate stress kinases or other signals, interfering with insulin action [11]. However, how ACs directly affect insulin mediated glucose uptake is currently unexplained.

Fasting increases plasma long-chain ACs [13-15], but it is unknown, whether muscle longchain ACs increase during short-term fasting in humans. Animal studies showed increased muscle long-chain AC levels during fasting [16;17]. Such an increase of ACs during fasting would match increased lipid oxidation and decreased peripheral insulin sensitivity $[1 ; 3 ; 4]$.

In this study, we examined the association of muscle ACs during short-term fasting with glucose and fat metabolism. Healthy lean subjects were studied before and after short-term fasting in both the basal state and during a hyperinsulinemic euglycemic clamp. We hypothesized that fasting induced an increase of whole body FAO resulting in an increase in muscle ACs which would explain the expected peripheral insulin resistance. 


\section{Materials and methods}

\section{Subjects}

We studied healthy lean male volunteers who participated in a study on fasting induced insulin resistance [4]. Subjects were in self-reported good health, confirmed by medical history and physical examination. Criteria for inclusion were 1) absence of a family history of diabetes; 2) age 18-35 yr; 3) Caucasian race; 4) BMI 20-25 kg/m²; 5) normal oral glucose tolerance test according to the ADA criteria [18]; 6) normal routine blood examination; 7) no excessive sport activities, i.e. $<3$ times per week; and 8) no medication. Written informed consent was obtained from all subjects after explanation of purposes, nature, and potential risks of the study. The study was approved by the Medical Ethical Committee of the Academic Medical Center of the University of Amsterdam.

\section{Experimental protocol}

Subjects were studied twice: after 14 and $62 \mathrm{~h}$ of fasting. Study days were separated by at least a week. Subjects were fasting from $2000 \mathrm{~h}$ the evening before the first study day and from $2000 \mathrm{~h}$ three days before the second study day until the end of the study days. They were allowed to drink water only.

After admission to the metabolic unit at $0730 \mathrm{~h}$, a catheter was inserted into an antecubital vein for infusion of stable isotope tracers, insulin and glucose. Another catheter was inserted retrogradely into a contralateral hand vein and kept in a thermo-regulated $\left(60^{\circ} \mathrm{C}\right)$ plexiglas box for sampling of arterialized venous blood. Saline was infused as $\mathrm{NaCl} 0.9 \%$ at a rate of 50 $\mathrm{mL} / \mathrm{h}$ to keep the catheters patent. $\left[6,6-{ }^{2} \mathrm{H}_{2}\right]$ glucose and $\left[1,1,2,3,3-{ }^{2} \mathrm{H}_{5}\right]$ glycerol were used as tracers ( $>99 \%$ enriched; Cambridge Isotopes, Andover, USA) to study glucose kinetics and lipolysis (total triglyceride hydrolysis) respectively.

At $\mathrm{T}=0 \mathrm{~h}(0800 \mathrm{~h})$, blood samples were drawn for determination of background enrichments and a primed continuous infusion of both isotopes was started: $\left[6,6-{ }^{2} \mathrm{H}_{2}\right]$ glucose (prime, 8.8 $\mu \mathrm{mol} / \mathrm{kg}$; continuous, $0.11 \mu \mathrm{mol} / \mathrm{kg} \cdot \mathrm{min}$ ) and $\left[1,1,2,3,3-{ }^{2} \mathrm{H}_{5}\right]$ glycerol (prime, $1.6 \mu \mathrm{mol} / \mathrm{kg}$; continuous, $0.11 \mu \mathrm{mol} / \mathrm{kg} \cdot \mathrm{min}$ ) and continued until the end of the study. After an equilibration period of two hours (14 h of fasting), 3 blood samples were drawn for glucose and glycerol enrichments and 1 for glucoregulatory hormones, FFA and plasma AC levels. Thereafter $(\mathrm{T}=$ $3 \mathrm{~h}$ ), infusions of insulin $\left(60 \mathrm{mU} / \mathrm{m}^{2} \cdot \mathrm{min}\right)$ (Actrapid $100 \mathrm{IU} / \mathrm{ml}$; Novo Nordisk Farma B.V., Alphen aan den Rijn, the Netherlands) and glucose 20\% (to maintain a plasma glucose level of $5 \mathrm{mmol} / \mathrm{L}$ ) were started. $\left[6,6{ }^{2} \mathrm{H}_{2}\right]$ glucose was added to the $20 \%$ glucose solution to achieve 
glucose enrichments of $1 \%$ to approximate the values for enrichment reached in plasma and thereby minimizing changes in isotopic enrichment due to changes in the infusion rate of exogenous glucose [19]. Plasma glucose levels were measured every $5 \mathrm{~min}$ at the bedside. At $\mathrm{T}=8 \mathrm{~h}, 5$ blood samples were drawn at 5-min intervals for determination of glucose and glycerol enrichments. Another blood sample was drawn for determination of glucoregulatory hormones, FFA and plasma AC levels.

Subjects were studied under the same conditions after $62 \mathrm{~h}$ of fasting. Volunteers were allowed to drink water ad libitum. To prevent sodium and potassium depletion during fasting, subjects were supplied with oral sodium chloride $80 \mathrm{mmol}$ per day (Tablets, In-House Pharmacist, AMC, Amsterdam, the Netherlands) and oral potassium chloride 40mmol per day (Slow-K, Novartis BV, Arnhem, the Netherlands).

\section{Indirect calorimetry and muscle biopsies}

Oxygen consumption $\left(\mathrm{VO}_{2}\right)$ and $\mathrm{CO}_{2}$ production $\left(V \mathrm{CO}_{2}\right)$ were measured continuously during the final $20 \mathrm{~min}$ of both the basal state and the clamp by indirect calorimetry using a ventilated hood system (Sensormedics model 2900; Sensormedics, Anaheim, CA).

Muscle biopsies were performed to assess muscle AC concentrations at the end of both the basal state and the clamp. Biopsies was performed under local anesthesia (lidocaine 20 $\mathrm{mg} / \mathrm{ml}$; Fresenius, Kabi, Den Bosch, The Netherlands) using a Pro-Mag I biopsy needle (MDTECH, Gainesville, FL). Biopsy specimens were quickly washed in a buffer $(0.9 \%$ $\mathrm{NaCl} / 28.3 \mathrm{~g} /$ liter HEPES) to remove blood, inspected for fat or fascia content, dried on gauze swabs, and subsequently stored in liquid nitrogen until analysis.

\section{Glucose and lipid metabolism measurements}

Plasma glucose and FFA concentrations were measured as described earlier [4]. [6,6-

${ }^{2} \mathrm{H}_{2}$ ]glucose enrichment was measured as described earlier [20]. [6,6- $\left.{ }^{2} \mathrm{H}_{2}\right]$ glucose enrichment (tracer/tracee ratio) intra-assay variation: $0.5-1 \%$; inter-assay variation $1 \%$; detection limit: $0.04 \%$. [1,1,2,3,3- ${ }^{2} \mathrm{H}_{5}$ ]glycerol enrichment was determined as described earlier [21]. Intraassay variation glycerol: $1-3 \%,\left[1,1,2,3,3-{ }^{2} \mathrm{H}_{5}\right]$ glycerol: $4 \%$; inter-assay variation glycerol: 2 $3 \% ;\left[1,1,2,3,3-{ }^{2} \mathrm{H}_{5}\right]$ glycerol: $7 \%$.

\section{Glucoregulatory hormones}

Insulin, glucagon, cortisol, norepinephrine and epinephrine were measured as described earlier [22]. 


\section{Plasma and muscle carnitine measurements}

AC plasma concentrations were analyzed as described previously [23]. Muscle biopsies were freeze dried and analyzed as described previously [24]. Total long-chain ACs represent the sum of $\mathrm{C}_{12: 1^{-}}, \mathrm{C}_{12^{-}}, \mathrm{C}_{14: 2^{-}}, \mathrm{C}_{14: 1^{-}}, \mathrm{C}_{14^{-}}, \mathrm{C}_{16: 1^{-}}, \mathrm{C}_{16^{-}}, \mathrm{C}_{18: 2^{-}}, \mathrm{C}_{18: 1^{-}}$and $\mathrm{C}_{18}$-carnitine.

\section{Calculations and statistics}

Endogenous glucose production (EGP) and rate of glucose disposal (Rd) were calculated using the modified forms of the Steele Equations as described previously [4;19;25]. EGP and $\mathrm{Rd}$ were expressed as $\mu \mathrm{mol} / \mathrm{kg} \cdot \mathrm{min}$. Rd was also expressed in relation to the plasma insulin levels (ratio Rd/insulin). Lipolysis (glycerol turnover) was calculated by using formulas for steady state kinetics adapted for stable isotopes (32). Lipolysis was expressed as $\mu \mathrm{mol} / \mathrm{kg} \cdot \mathrm{min}$ and as $\mu \mathrm{mol} / \mathrm{kcal}$ as proposed by Koutsari et al (30).

Resting energy expenditure (REE) was expressed as kcal/day. FAO and $\mathrm{CHO}$ rates were calculated from $\mathrm{O}_{2}$ consumption and $\mathrm{CO}_{2}$ production [26].

Statistical comparisons and correlation analyses were performed with the Wilcoxon Signed Rank test and Spearman's rank correlation coefficient $(\rho)$ respectively. The SPSS statistical software program version 12.0.2 (SPSS Inc, Chicago, IL) was used for statistical analysis. Data are presented as median [minimum - maximum]. 


\section{Results}

\section{Anthropometric characteristics}

The subject characteristics have been reported earlier [4]: In sum, subject characteristics were: age: 23 [20 - 26] yrs; weight 70.1 [62.5 - 75.5] kg after $14 \mathrm{~h}$ and 69.0 [60.0 - 72.8] kg after $62 \mathrm{~h}$ of fasting, $P=0.012$; BMI $20.9[19.2-23.3] \mathrm{kg} / \mathrm{m}^{2}$ after $14 \mathrm{~h}$ and 20.3 [18.3 - 22.6] $\mathrm{kg} / \mathrm{m}^{2}$ after $62 \mathrm{~h}$ of fasting, $P=0.011$.

\section{Indirect calorimetry}

REE (kcal/day) in the basal state was significantly higher after $62 \mathrm{~h}$ of fasting compared to 14 $\mathrm{h}$ of fasting; 1682 [1518 - 1820] kcal/day vs. 1578 [1308 - 1783] kcal/day respectively, $P=$ 0.017 (Figure 1). During the clamp however, REE was significantly lower after $62 \mathrm{~h}$ of fasting compared to $14 \mathrm{~h}$ of fasting; 1604 [1470 - 1734] kcal/day vs. 1815 [1494 - 1933] $\mathrm{kcal} /$ day respectively, $P=0.012$.

FAO $(\mu \mathrm{mol} / \mathrm{kg} \cdot \mathrm{min})$ in the basal state was significantly higher after $62 \mathrm{~h}$ of fasting compared to $14 \mathrm{~h}$ of fasting (Figure 1). During the clamp, FAO remained significantly higher after $62 \mathrm{~h}$ of fasting compared to $14 \mathrm{~h}$ of fasting. The absolute change during the clamps in FAO was not different between 62 and $14 \mathrm{~h}$ of fasting; -5.1 [-6.6 - -2.7] $\mu \mathrm{mol} / \mathrm{kg} \cdot \mathrm{min}$ vs. -3.9 [-4.8 - 1.0] $\mu \mathrm{mol} / \mathrm{kg} \cdot \min$ respectively, $P=0.8$. CHO was significantly lower after $62 \mathrm{~h}$ of fasting compared to $14 \mathrm{~h}$ of fasting (Figure 1). During the clamp, CHO was significantly lower after $62 \mathrm{~h}$ of fasting compared to $14 \mathrm{~h}$ of fasting. The absolute change between the basal state and the clamp in $\mathrm{CHO}$ was not different between 62 and $14 \mathrm{~h}$ of fasting: 12.8 [5.9 - 17.1] $\mu \mathrm{mol} / \mathrm{kg} \cdot \mathrm{min}$ vs. $13.6[7.5-19.3] \mu \mathrm{mol} / \mathrm{kg} \cdot \mathrm{min}$ respectively, $P=0.2$.

If $\mathrm{FAO}$ and $\mathrm{CHO}$ were expressed as $\mu \mathrm{mol} / \mathrm{kg} \mathrm{LBM} \cdot \mathrm{min}$ comparable results were obtained (data not shown).

\section{Glucose and lipid metabolism measurements}

Plasma glucose concentrations and EGP (Table 1) were significantly lower after $62 \mathrm{~h}$ of fasting compared to $14 \mathrm{~h}$ fasting [4]. No differences were found in plasma glucose concentrations after $62 \mathrm{~h}$ vs. $14 \mathrm{~h}$ of fasting during the clamp. Rd during the clamp was significantly lower after $62 \mathrm{~h}$ of fasting compared to $14 \mathrm{~h}$ of fasting (Table 1). The ratio $\mathrm{Rd} /$ insulin was significantly lower after $62 \mathrm{~h}$ of fasting compared to $14 \mathrm{~h}$ of fasting: 0.079 [0.069 - 0.116] vs. $0.090[0.072-0.18]$ respectively, $P=0.036$.

Basal plasma FFA and rate of lipolysis were significantly higher after $62 \mathrm{~h}$ of fasting (Table 1). Plasma FFA were suppressed during the hyperinsulinaemic euglycaemic clamps after $62 \mathrm{~h}$ 
and $14 \mathrm{~h}$ of fasting (Table 1). Lipolysis was not different after $62 \mathrm{~h}$ of fasting compared to 14 $\mathrm{h}$ of fasting during the clamp (Table 1).

\section{Glucoregulatory hormones}

Insulin was significantly lower after $62 \mathrm{~h}$ of fasting in the basal state as well as during the clamp (Table 1). Other data on glucoregulatory hormones have been presented elsewhere [4].

\section{Muscle and plasma carnitines}

After $62 \mathrm{~h}$ of fasting, muscle free carnitine (FC) was higher compared to $14 \mathrm{~h} ; 9503$ [5326 14360] pmol/mg dry weight vs. 5299 [3331 - 7051] pmol/mg dry weight respectively, $P=$ 0.028. During the clamp muscle FC was not different after $62 \mathrm{~h}$ of fasting compared to $14 \mathrm{~h}$ of fasting; 7095 [2559 - 12278] pmol/mg dry weight vs. 6408 [4189 - 8621] pmol/mg dry weight, $P=0.16$. After $14 \mathrm{~h}$ of fasting, hyperinsulinemia during the clamp tended to increase muscle FC levels compared to the basal state, but this was not statistically significant $(P=$ 0.06). Muscle FC did not change between the basal state and the clamp after $62 \mathrm{~h}$ of fasting ( $P$ $=0.22$ ).

Basal muscle acetyl-carnitine was significantly higher after $62 \mathrm{~h}$ of fasting compared to $14 \mathrm{~h}$; 1175 [411 - 3380] pmol/mg dry weight vs. 697 [269 - 1149] pmol/mg dry weight respectively, $P=0.05$. Clamp muscle acetyl-carnitine was significantly lower after $62 \mathrm{~h}$ of fasting compared to $14 \mathrm{~h} ; 316$ [170 - 632] pmol/mg dry weight vs. 513 [335 - 959] pmol/mg dry weight respectively, $P=0.021$. After $14 \mathrm{~h}$ of fasting, hyperinsulinemia during the clamp did not change acetyl-carnitine levels compared to the basal state $(P=0.25)$, whereas the clamp decreased muscle acetyl-carnitine compared to the basal state after $62 \mathrm{~h}$ of fasting $(P=$ $0.017)$.

In the basal state muscle long-chain ACs were not significantly different after $62 \mathrm{~h}$ vs. $14 \mathrm{~h}$ of fasting (Figure 2). Total muscle long-chain ACs were significantly higher during the clamp after $62 \mathrm{~h}$ of fasting compared to $14 \mathrm{~h}$ of fasting (Figure 2). Individual muscle long-chain ACs showed a similar pattern (Table 2).

Total plasma long-chain ACs were significantly higher after $62 \mathrm{~h}$ of fasting compared to $14 \mathrm{~h}$ of fasting in the basal state and during the clamp. The same was true for individual plasma long-chain ACs (data not shown).

Muscle long-chain acylcarnitines did not correlate with lipolysis, Rd, FAO or plasma longchain acylcarnitines (data not shown). 


\section{Discussion}

In the present study, muscle long-chain acylcarnitines after 14 and 62 hours of fasting were studied and correlated to glucose and fatty acid oxidation rates as well as peripheral insulin sensitivity. In the basal state, there was no significant difference in muscle long-chain ACs between 14 and $62 \mathrm{~h}$ of fasting. In contrast during hyperinsulinemia we found a decrease in muscle long-chain ACs after $14 \mathrm{~h}$ of fasting versus no changes in muscle long-chain ACs after $62 \mathrm{~h}$ of fasting was found. The latter finding was accompanied by higher whole body FAO.

REE increased approximately $7.5 \%$ during $62 \mathrm{~h}$ of fasting, which is in line with previous observations [3;27-29], although the increase in REE has not fully been accounted for. It was proposed that increased energy requirements of gluconeogenesis and ketogenesis are reflected in increased REE [27;28]. On the other hand it was suggested that the norepinephrine induced thermogenic response results in a slight increase in REE during short-term fasting [27;29], but we did not detect differences in plasma norepinephrine [4].

Our study confirmed earlier reports on increased plasma FFA and lipolysis [1]. Higher plasma FFA are also found in different models of insulin resistance and are thought to be one of the main mediators of obesity-induced insulin resistance [30]. Lipid mediators that induce insulin resistance are mainly derived from long-chain fatty acids [31]. Moreover, muscle long-chain ACs have been suggested to induce peripheral insulin resistance in animal studies $[8 ; 11 ; 12]$. Since fasting induces insulin-resistance [2;4], we hypothesized that this may be related to an increase in muscle long-chain ACs. Human data on muscle ACs during fasting are lacking but previous animal studies showed an increase of muscle long-chain ACs in rodents after fasting $[8 ; 17]$.

The lack of an increase in muscle long-chain ACs between 14 and $62 \mathrm{~h}$ of fasting is unexpected since we demonstrated an increase in whole body FAO. The CPT1 dependent rate of long-chain fatty acid entrance into the mitochondria is thought to determine the rate of FAO [5;7]. Our data imply that the muscle concentration of ACs during fasting in humans does not reflect whole body FAO.

Hyperinsulinemia resulted in a decreased concentration of long-chain muscle ACs after $14 \mathrm{~h}$ of fasting. Other studies did not find a decrease in ACs during hyperinsulinemia [32]. This may be explained by differences in the methods to analyze muscle ACs. Another possibility includes that we measured muscle ACs of chain-length 12 to 18 in contrast to all muscle ACs. After $62 \mathrm{~h}$ of fasting, the suppressive effect of insulin on muscle long-chain ACs was not found. Increased muscle long- chain ACs during the clamp after $62 \mathrm{~h}$ of fasting are unlikely to reflect accumulation of non utilizable long-chain ACs or ongoing FAO since we could not 
demonstrate such a relationship in the basal state after $62 \mathrm{~h}$ of fasting. Although indirect calorimetry does not reflect muscle FAO only, ongoing FAO is likely to occur since clamp values of whole body FAO were higher after $62 \mathrm{~h}$ of fasting compared to $14 \mathrm{~h}$ of fasting. This suggests that despite $5 \mathrm{~h}$ of hyperinsulinemia, peripheral glucose uptake is still attenuated and activated fatty acids are continued to be transported to the mitochondrion in order to be oxidized [5;7]. Ongoing FAO may be needed since peripheral glucose uptake is attenuated. Our data on increased plasma long-chain ACs after $62 \mathrm{~h}$ of fasting confirm older studies [1315]. In contrast to our finding in muscle, plasma long-chain ACs were higher after 62 compared to $14 \mathrm{~h}$ of fasting, but decreased equally during hyperinsulinemia. This, and the absence of a correlation of plasma ACs with muscle ACs negates that plasma ACs reflect muscle ACs. It may support the notion that the liver is the most likely source of plasma longchain ACs during short-term fasting [7;33;34].

No human studies are available on muscle FC during fasting, however it was shown in animal studies that muscle FC increases during fasting [17;35]. Moreover, the plasma membrane transporter of carnitine (OCTN2) is upregulated by fasting in a PPAR-alpha dependent mechanism [36]. Indeed, in our subjects, muscle FC increased during $62 \mathrm{~h}$ compared to 14 of fasting. This may reflect the dependence of FAO on FC for transport of long-chain acyl-CoAs across the mitochondrial membranes. However, the exact mechanism remains elusive.

We found lower insulin levels during the clamp after $62 \mathrm{~h}$ of fasting that are unlikely to interfere with our results. Since insulin infusions were almost identical this may be due to increased renal clearance of infused insulin in contrast to the first pass effect of endogenous insulin by the liver [37]. Fasting is generally known to induce insulin resistance [3]. In our experience infusing insulin at a rate of $60 \mathrm{mU} / \mathrm{m}^{2} \cdot \mathrm{min}$ does not augment glucose disposal significantly compared to $40 \mathrm{mU} / \mathrm{m}^{2}$ : both infusion rates yield similar disposal rates after an overnight fast, despite very different plasma insulin levels [38]. This may be explained by the shape of the dose response curve for insulin. Moreover, when standardized to the plasma insulin levels, $\mathrm{Rd}$ was lower after $62 \mathrm{~h}$ of fasting.

In conclusion we show that fasting for $62 \mathrm{~h}$ results in higher rates of lipolysis and FAO together with lower $\mathrm{CHO}$ rates and lower peripheral insulin sensitivity. These rates are not paralleled with an increase in muscle long-chain ACs after $62 \mathrm{~h}$ of fasting in the basal state. However, during hyperinsulinemia, the suppression of the concentration of muscle long-chain ACs was less compared to after $14 \mathrm{~h}$ of fasting. Also, whole body FAO rates remained higher during the clamp after $62 \mathrm{~h}$ of fasting. Despite earlier reports on possible interference of the muscle long-chain ACs with peripheral insulin sensitivity, our study does not support such a 
role for muscle long-chain ACs during fasting. To clarify whether muscle ACs are just innocent bystanders or active players in insulin resistance, further studies in different models of insulin resistance are needed.

\section{Acknowledgements}

We thank A.F.C Ruiter and M. Doolaard for excellent assistance on laboratory analyses of stable isotopes and acylcarnitines respectively.

\section{Disclosure statement:}

The authors have nothing to disclose. 
Reference List

1 Klein,S., Sakurai,Y., Romijn,J.A. and Carroll,R.M. (1993) Progressive alterations in lipid and glucose metabolism during short-term fasting in young adult men. Am J Physiol Endocrinol Metab, 265, E801-E806.

2 Bjorkman,O. and Eriksson,L.S. (1985) Influence of a 60-hour fast on insulin-mediated splanchnic and peripheral glucose metabolism in humans. J.Clin.Invest, 76, 87-92

3 Bergman,B.C., Cornier,M.A., Horton,T.J. and Bessesen,D.H. (2007) Effects of fasting on insulin action and glucose kinetics in lean and obese men and women. Am J Physiol Endocrinol Metab, 293, E1103-E1111.

4 Soeters,M.R., Sauerwein,H.P., Dubbelhuis,P.F., Groener,J.E., Ackermans,M.T., Fliers,E., Aerts,J.M. and Serlie,M.J. (2008) Muscle Adaptation to Short-Term Fasting in Healthy Lean Humans. J Clin Endocrinol Metab, 93, 2900-2903.

5 Stephens,F.B., Constantin-Teodosiu,D. and Greenhaff,P.L. (2007) New insights concerning the role of carnitine in the regulation of fuel metabolism in skeletal muscle. J Physiol, 581, 431-444.

6 Ramsay,R.R., Gandour,R.D. and van der Leij,F.R. (2001) Molecular enzymology of carnitine transfer and transport. Biochim.Biophys.Acta., 1546, 21-43.

7 Eaton,S. (2002) Control of mitochondrial beta-oxidation flux. Progress in Lipid Research, 41, 197-239.

8 Koves,T.R., Ussher,J.R., Noland,R.C., Slentz,D., Mosedale,M., Ilkayeva,O., Bain,J., Stevens,R., Dyck,J.R., Newgard,C.B., Lopaschuk,G.D. and Muoio,D.M. (2008)

Mitochondrial overload and incomplete fatty acid oxidation contribute to skeletal muscle insulin resistance. Cell Metab., 7, 45-56.

9 Bartlett,K. and Pourfarzam,M. (1999) Tandem mass spectrometry ГÇö The potential. Journal of Inherited Metabolic Disease, 22, 568-571.

10 Bartlett,K., Eaton,S.J and Pourfarzam,M. (1997) New developments in neonatal screening. Arch.Dis.Child.Fetal Neonatal Ed., 77, F151-F154.

11 Muoio,D.M. and Koves, T.R. (2007) Lipid-induced metabolic dysfunction in skeletal muscle. Novartis.Found.Symp., 286:24-38; discussion 38-46, 162-3, 196-203.

12 An,J., Muoio,D.M., Shiota,M., Fujimoto,Y., Cline,G.W., Shulman,G.I., Koves,T.R., Stevens,R., Millington,D. and Newgard,C.B. (2004) Hepatic expression of malonyl-CoA decarboxylase reverses muscle, liver and whole-animal insulin resistance. Nat Med, 10, 268274.

13 Hoppel, C.L. and Genuth,S.M. (1980) Carnitine metabolism in normal-weight and obese human subjects during fasting. Am.J.Physiol., 238, E409-E415. 
14 Frohlich,J., Seccombe,D.W., Hahn,P., Dodek,P. and Hynie,I. (1978) Effect of fasting on free and esterified carnitine levels in human serum and urine: Correlation with serum levels of free fatty acids and [beta]-hydroxybutyrate. Metabolism, 27, 555-561.

15 Costa,C.C.G., De Almeida,I.T., Jakobs,C.O.R.N., Poll-The,B.-T. and Duran,M. (1999) Dynamic Changes of Plasma Acylcarnitine Levels Induced by Fasting and Sunflower Oil Challenge Test in Children. Pediatric Research, 46, 440.

16 Erfle,J.D. and Sauer,F. (1967) Acetyl Coenzyme A and Acetylcarnitine Concentration and Turnover Rates in Muscle and Liver of the Ketotic Rat and Guinea Pig. J.Biol.Chem, 242, 1988-1996.

17 Kerner,J. and Bieber,L.L. (1983) The effect of electrical stimulation, fasting and anesthesia on the carnitine(s) and acyl-carnitines of rat white and red skeletal muscle fibres. Comp Biochem.Physiol B., 75, 311-316.

18 Anonymous(2003) Report of the Expert Committee on the Diagnosis and Classification of Diabetes Mellitus. Diabetes Care, 26, 5S-20.

19 Finegood,D.T., Bergman,R.N. and Vranic,M. (1987) Estimation of endogenous glucose production during hyperinsulinemic-euglycemic glucose clamps. Comparison of unlabeled and labeled exogenous glucose infusates. Diabetes., 36, 914-924.

20 Ackermans,M.T., Pereira Arias,A.M., Bisschop,P.H., Endert,E., Sauerwein,H.P. and Romijn,J.A. (2001) The quantification of gluconeogenesis in healthy men by (2)H2O and [2(13)C]glycerol yields different results: rates of gluconeogenesis in healthy men measured with (2) $\mathrm{H} 2 \mathrm{O}$ are higher than those measured with [2-(13)C]glycerol. J Clin.Endocrinol Metab., 86, 2220-2226.

21 Ackermans,M.T., Ruiter,A.F. and Endert,E. (1998) Determination of glycerol concentrations and glycerol isotopic enrichments in human plasma by gas chromatography/mass spectrometry. Anal.Biochem., 258, 80-86.

22 Soeters,M.R., Sauerwein,H.P., Groener,J.E., Aerts,J.M., Ackermans,M.T., Glatz,J.F.C., Fliers,E. and Serlie,M.J. (2007) Gender-Related Differences in the Metabolic Response to Fasting. J Clin Endocrinol Metab, 92, 3646-3652.

23 Vreken,P., van Lint,A.E., Bootsma,A.H., Overmars,H., Wanders,R.J. and van Gennip,A.H. (1999) Quantitative plasma acylcarnitine analysis using electrospray tandem mass spectrometry for the diagnosis of organic acidaemias and fatty acid oxidation defects. $\mathrm{J}$ Inherit.Metab Dis., 22, 302-306.

24 van Vlies,N., Tian,L., Overmars,H., Bootsma,A.H., Kulik,W., Wanders,R.J.A., Wood,P.A. and Vaz,F.d.r.M. (2005) Characterization of carnitine and fatty acid metabolism in the longchain acyl-CoA dehydrogenase-deficient mouse. Biochem.J., 387, 185-193.

25 Steele,R. (1959) Influences of glucose loading and of injected insulin on hepatic glucose output. Ann.N Y.Acad.Sci., 82:420-30., 420-430.

26 Frayn,K.N. (1983) Calculation of substrate oxidation rates in vivo from gaseous exchange. J Appl Physiol, 55, 628-634. 
27 Webber,J., Taylor,J., Greathead,H., Dawson,J., Buttery,P.J. and Macdonald,I.A. (1994) Effects of fasting on fatty acid kinetics and on the cardiovascular, thermogenic and metabolic responses to the glucose clamp. Clin Sci.(Lond)., 87, 697-706.

28 Mansell,P.I. and Macdonald,I.A. (1990) The effect of starvation on insulin-induced glucose disposal and thermogenesis in humans. Metabolism, 39, 502-510.

29 Zauner,C., Schneeweiss,B., Kranz,A., Madl,C., Ratheiser,K., Kramer,L., Roth,E. Schneider,B. and Lenz,K. (2000) Resting energy expenditure in short-term starvation is increased as a result of an increase in serum norepinephrine. Am J Clin Nutr, 71, 1511-1515.

30 Boden,G. (2002) Interaction between free fatty acids and glucose metabolism. Curr.Opin.Clin.Nutr.Metab Care., 5, 545-549.

31 Holland,W.L., Knotts,T.A., Chavez,J.A., Wang,L.P., Hoehn,K.L. and Summers,S.A. (2007) Lipid Mediators of Insulin Resistance. Nutrition Reviews, 65, 39-46.

32 Stephens,F.B., Constantin-Teodosiu,D., Laithwaite,D., Simpson,E.J. and Greenhaff,P.L. (2006) An Acute Increase in Skeletal Muscle Carnitine Content Alters Fuel Metabolism in Resting Human Skeletal Muscle. J Clin Endocrinol Metab, 91, 5013-5018.

33 Bartlett,K., Bhuiyan,A.K., ynsley-Green,A., Butler,P.C. and Alberti,K.G. (1989) Human forearm arteriovenous differences of carnitine, short-chain acylcarnitine and long-chain acylcarnitine. Clin Sci.(Lond), 77, 413-416.

34 Eaton,S., Bartlett,K., Pourfarzam,M., Markley,M.A., New,K.J. and Quant,P.A. (1999) Production and export of acylcarnitine esters by neonatal rat hepatocytes. Adv.Exp.Med Biol., 466, 155-159.

35 Luci,S., Hirche,F. and Eder,K. (2008) Fasting and caloric restriction increases mRNA concentrations of novel organic cation transporter-2 and carnitine concentrations in rat tissues. Ann.Nutr Metab., 52, 58-67.

36 Ringseis,R., Wege,N., Wen,G., Rauer,C., Hirche,F., Kluge,H. and Eder,K. Carnitine synthesis and uptake into cells are stimulated by fasting in pigs as a model of nonproliferating species. The Journal of Nutritional Biochemistry, doi:10.1016/j.jnutbio.2008.07.012.

37 Duckworth,W.C., Bennett,R.G. and Hamel,F.G. (1998) Insulin Degradation: Progress and Potential. Endocr Rev, 19, 608-624.

38 Stegenga,M.E., van der Crabben,S.N., Levi,M., de Vos,A.F., Tanck,M.W., Sauerwein,H.P. and van der Poll,T. (2006) Hyperglycemia Stimulates Coagulation, Whereas

Hyperinsulinemia Impairs Fibrinolysis in Healthy Humans. Diabetes, 55, 1807-1812. 


\section{FIGURE LEGENDS}

Figure 1, panel A Resting energy expenditure (REE) in the basal state and during the clamp after $14 \mathrm{~h}$ (open box plots) and $62 \mathrm{~h}$ (grey boxplots) of fasting. ${ }^{*} P=0.017$ and 0.012 respectively. ${ }^{* *} P=0.017$ for the increase and 0.05 for the decrease of REE during the clamps after 62 and $14 \mathrm{~h}$ of fasting respectively.

Figure 1, panel B Fat oxidation in the basal state and during the clamp after $14 \mathrm{~h}$ (open box plots) and $62 \mathrm{~h}$ (grey boxplots) of fasting. $* P=0.012$ and 0.017 respectively. $* * P=0.012$ for the decrease of fat oxidation during both clamps after 62 and $14 \mathrm{~h}$ of fasting.

Figure 1, panel $\mathbf{C ~ C H O}$ in the basal state and during the clamp after $14 \mathrm{~h}$ (open box plots) and $62 \mathrm{~h}$ (grey boxplots) of fasting, $* P=0.012 . * * P=0.012$ for the increase of CHO during both clamps after 62 and $14 \mathrm{~h}$ of fasting.

Figure 2, panel A Total long chain plasma acylcarnitines (ACs) the basal state and during the clamp after $14 \mathrm{~h}$ (open box plots) and $62 \mathrm{~h}$ (grey boxplots) of fasting, ${ }^{*} P=0.012$. $* * P=$ 0.012 for the decrease of ACs during both clamps after 62 and 14 h of fasting.

Figure 2, panel B Total long chain muscle acylcarnitines (ACs) the basal state and during the clamp after $14 \mathrm{~h}$ (open box plots) and $62 \mathrm{~h}$ (grey boxplots) of fasting, ${ }^{*} P=0.012$ for the difference in ACs during the clamp between 62 and $14 \mathrm{~h}$ of fasting. $* * * P=0.05$ for the decrease in ACs between basal state and clamp after $14 \mathrm{~h}$ of fasting. 
Table 1 Glucose and lipid metabolism measurements

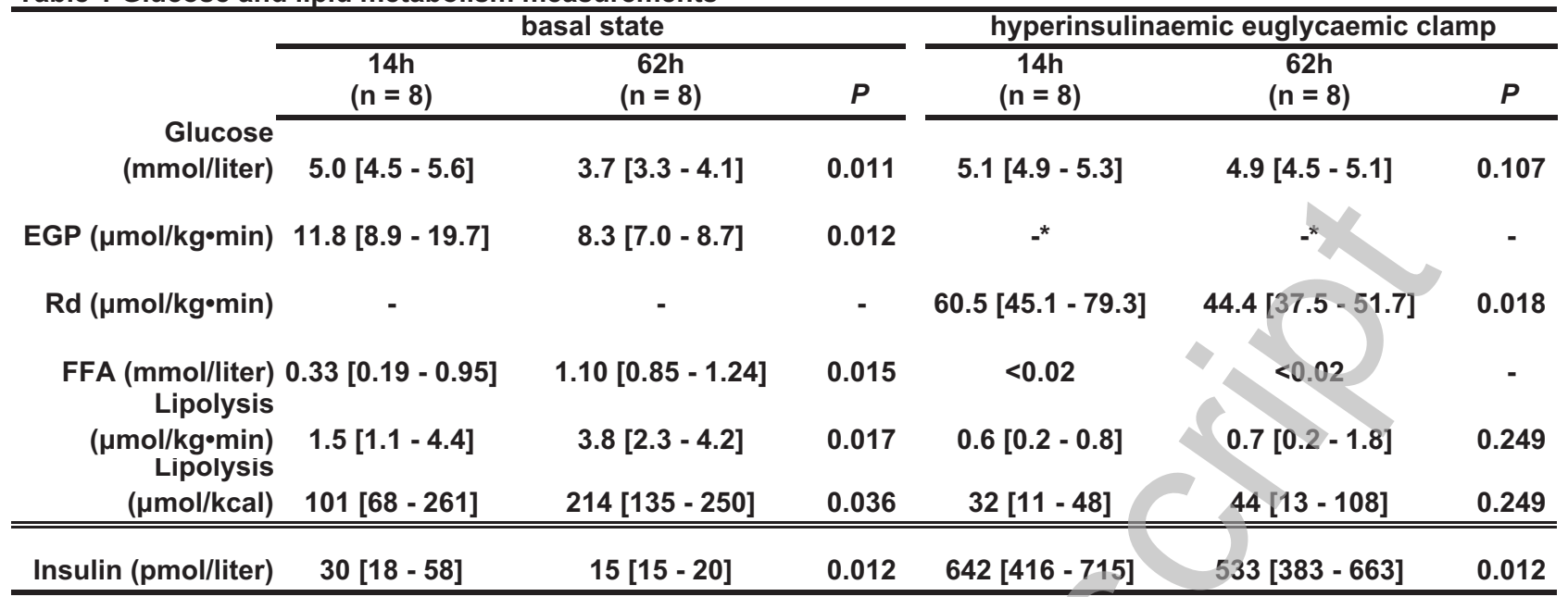

Data are presented as median [minimum - maximum]. EGP, endogenous glucose production; Rd, rate of disposal; FFA, free fatty acids. * During the clamps, EGP and FFA were completely suppressed. 


\begin{tabular}{|c|c|c|c|c|c|c|c|c|}
\hline \multirow{2}{*}{$\begin{array}{l}\text { Acylc } \\
\text { arniti } \\
\text { ne }\end{array}$} & \multicolumn{3}{|c|}{ basal state } & \multicolumn{3}{|c|}{ hyperinsulinemic euglycemic clamp } & \multirow[b]{2}{*}{$P^{c}$} & \multirow[b]{2}{*}{$P^{d}$} \\
\hline & $14 \mathrm{~h}$ & $62 \mathrm{~h}$ & $P^{a}$ & $14 \mathrm{~h}$ & $62 \mathrm{~h}$ & $P^{b}$ & & \\
\hline $\mathrm{C}_{12: 1}$ & $1.21[0.13-4.27]$ & $1.17[0.14-2.97]$ & 0.78 & $0.15[0-1.25]$ & $0.71[0.21-2.63]$ & 0.012 & 0.025 & 0.26 \\
\hline $\mathrm{C}_{12}$ & $4.15[0.13-14.69]$ & $2.42[0.42-7.97]$ & 0.48 & $0.26[0.18-6.41]$ & $1.45[0.21-5.38]$ & 0.16 & 0.069 & 0.48 \\
\hline $\mathrm{C}_{14: 2}$ & $2.05[0.13-9.24]$ & $1.19[0.31-5.51]$ & 0.58 & $0.15[0-3.59]$ & $0.97[0.11-4.00]$ & 0.036 & 0.050 & 0.40 \\
\hline $\mathrm{C}_{14: 1}$ & $7.6[0.25-37.68]$ & $4.68[0.56-20.00]$ & 0.89 & $0.17[0.12-10.94]$ & $3.41[0.32-9.00]$ & 0.036 & 0.036 & 0.33 \\
\hline $\mathrm{C}_{14}$ & $6.12[0.25-35.31]$ & $4.15[0.51-16.61]$ & 0.67 & $0.22[0.12-13.44]$ & $2.77[0.32-9,75]$ & 0.16 & 0.12 & 0.40 \\
\hline$C_{16: 1}$ & $6.18[0.13-46.45]$ & $4.59[0.61-22.80]$ & 1.00 & $0.30[0.13-14.92]$ & $2.48[0.21-14.00]$ & 0.069 & 0.093 & 0.67 \\
\hline $\mathrm{C}_{16}$ & $10.07[0.88-72.80]$ & $6.46[2.50-29.41]$ & 0.67 & $1.38[0.42-20.15]$ & $9.41[1.60-33.13]$ & 0.012 & 0.025 & 0.67 \\
\hline $\mathrm{C}_{18: 2}$ & $3.42[0.25-19.91]$ & $1.84[0.56-6.44]$ & 0.58 & $0.71[0.23-5.39]$ & $2.40[0.32-12.63]$ & 0.012 & 0.036 & 0.78 \\
\hline $\mathrm{C}_{18: 1}$ & $8.10[0.25-88.86]$ & $7.42[2.36-37.12]$ & 0.67 & $1.56[0.58-20.00]$ & $6.18[0.96-32.63]$ & 0.012 & 0.036 & 0.48 \\
\hline $\mathrm{C}_{18}$ & $3.46[0.25-25.36]$ & $2.32[0.97-7.29]$ & 0.40 & $1.18[0.47-5.39]$ & $3.04[0.85-9.50]$ & 0.012 & 0.017 & 0.33 \\
\hline
\end{tabular}

Data are presented as median [minimum - maximum]. ${ }^{\mathrm{a}, \mathrm{b}} \mathrm{P}$-values represent differences between basal states and clamps after 14 and $62 \mathrm{~h}$ of fasting respectively. ${ }^{\mathrm{c}, \mathrm{d}} P$-values represent differences within clamps after 14 and $62 \mathrm{~h}$ respectively. 


\section{FIGURE 1}

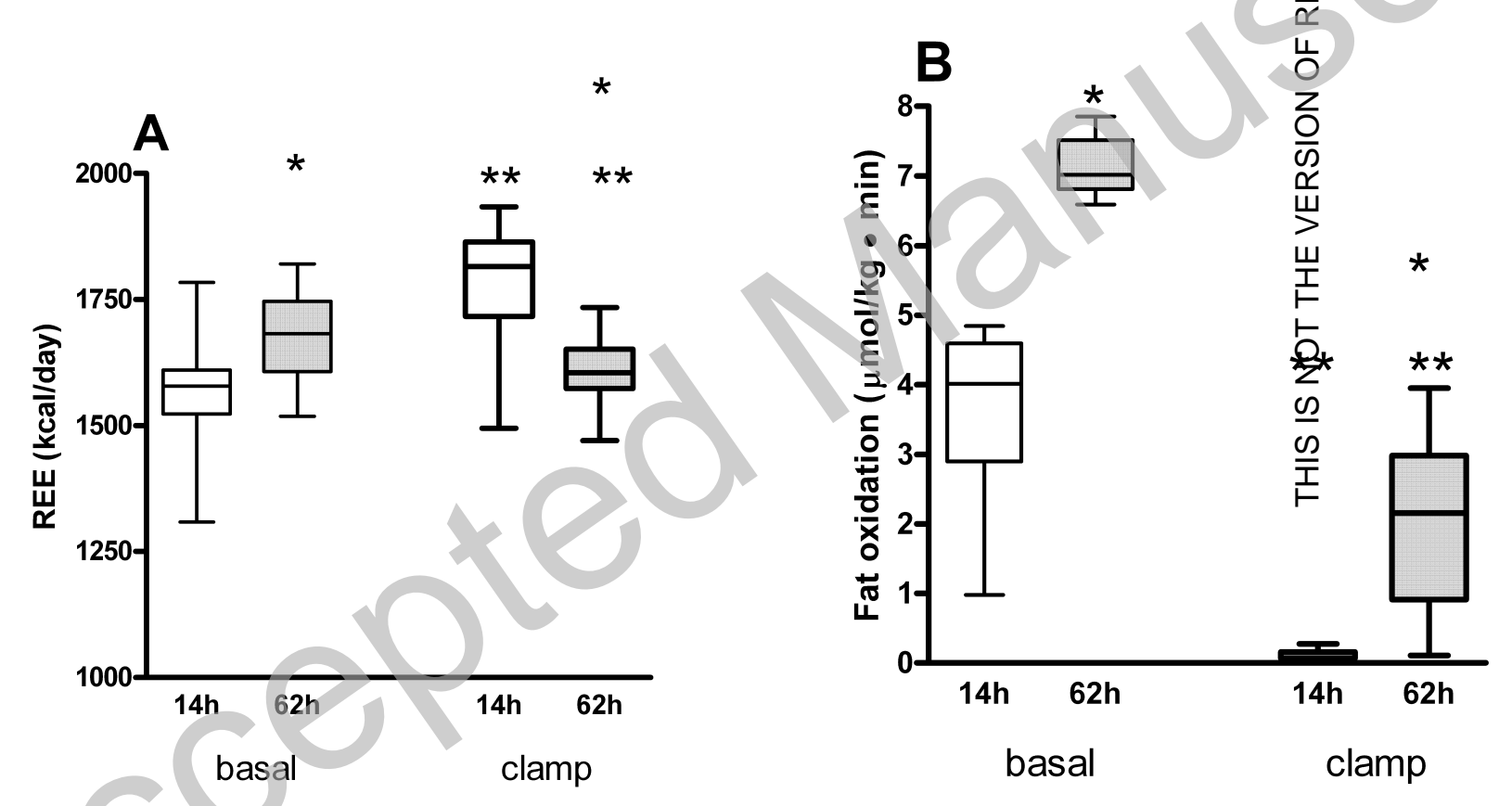




\section{FIGURE 2}
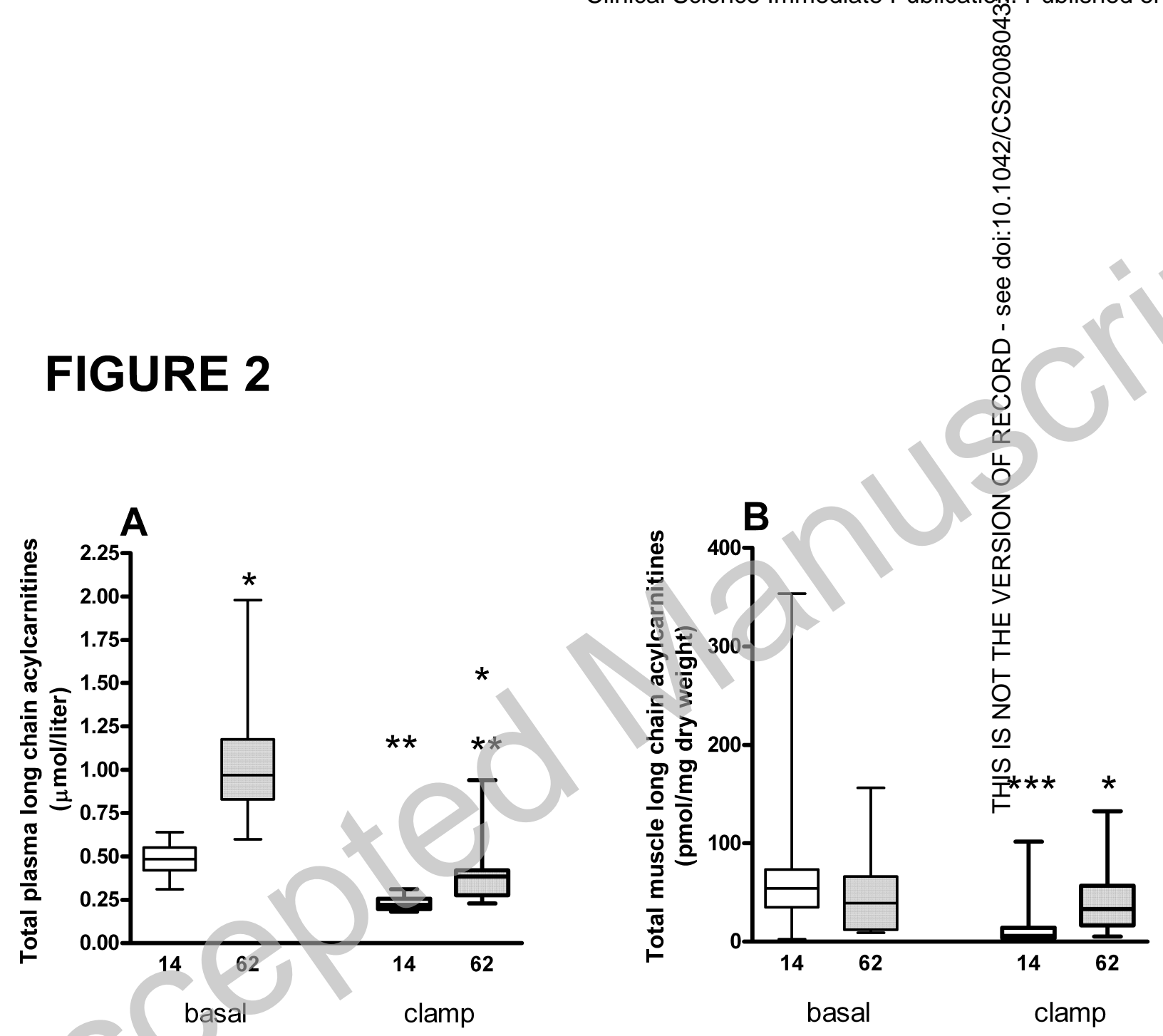